\title{
Light clay straw bale solutions in the contemporary housing as an element of sustainable development. Selected issues
}

\author{
Wojciech Drozd ${ }^{1, b}$ \\ ${ }^{1}$ Institute of Building and Transport Management, Tadeusz Kościuszko Cracow University of Technology, Warszawska 24 St., 31-155 \\ Kraków, Poland
}

\begin{abstract}
The article presents issues related to the solutions with light clay and straw bale in the contemporary housing. Building using straw bale and light clay is simple, eco-friendly and accessible to all. It fits in with the idea of sustainable development, supporting local businesses and giving people the opportunity to integrate in the design and construction of the house. The article presents the thermal analysis for both walls made of straw bale and of light clay. The analysis showed a very good performance. All positive aspects allow treating straw and light clay as a viable alternative to the commonly used technologies for erecting buildings.
\end{abstract}

\section{Low-tech, a natural way of building}

Modern material and technological solutions - concrete, steel, glass as well as intelligent systems have become the synonyms of modernity and luxury[1]. Low-tech is on the other extreme of modern construction. Low-tech solutions are based primarily on tradition and local, lowcost raw materials that do not require special treatment, which are readily available, such as soil, clay, straw and sand. Human hands are the main building force, while the use of complicated techniques or expensive expertise is limited. Family, friends, or neighbours may be involved in the construction process, which largely reduces the cost of construction. Low-tech construction skips complex technical solutions and supports natural, generally accessible, raw materials. The construction market, dominated by giant construction companies, does not support the development of such solutions, which are not profitable. This makes it difficult to popularise this building method on a large scale. Despite this, low-tech buildings are becoming more common and perfectly fit into the idea of sustainable development.

Sustainable development means "socio-economic development, where political, economic and social actions are integrated, while maintaining environmental balance and sustainability of basic natural processes, in order to guarantee the ability to meet basic needs of individual communities or citizens of the present generation and future generations ${ }^{a "}$. The most important features of a building characterised by sustainable development can be described using four R's: reduce, reuse, recycle and

${ }^{a}$ Environmental Protection Act Article 3 Section 50 recover ${ }^{c}$. Less material and energy is used to build such a building compared to conventional construction. The materials used should be recycled and should allow for re-use after the end of the life of the building. Natural construction derives the materials from the surrounding environment. Straw, clay, or wood is obtained from local, often family businesses. This supports local development and cultural independence of the region. Natural low-tech construction is friendly to the environment. Production of materials does not require high energy and high temperature processed, does not produce $\mathrm{CO}_{2}$, so it consumes less energy needed to construct the building than conventional building construction. Transport of materials is only done locally. And the structure itself is completely biodegradable and after the end of its life it does not leave harmful waste, hard to break down by the environment. Natural building allows for carrying out a lot of the work on one's own or with the help of not necessarily highly skilled people. It is available to all, creates local jobs and integrates people. The building material is cheap. All these features are very characteristic for sustainable development [3].

In the context of sustainable development in each of the stages of evaluation: design, construction, operation, points are awarded for the same use of natural materials.

In the selected issue some of the parameters of the envelope of natural materials were compared such as: clay and straw, in accordance with the procedures of evaluation: LEED, BREEAM, DNGB (The world's foremost environmental assessment method and rating system for buildings). In the article the heat transfer

\footnotetext{
${ }^{\mathrm{c}}$ Jerzy Baryłka, ,Environmental requirements in the construction industry as an example of construction law and the law on construction products"
}

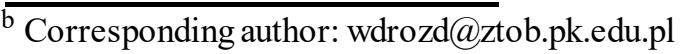


coefficient $U$, which determines the operation of the facility as a result of the impact on the environment, was analyzed.

\section{Thermal and moisture properties of building partitions}

The PN-EN ISO 6946 [4] standard provides a method for calculating the thermal resistance and heat transfer coefficient of building components that separate the internal and external environment, with the exception of doors, windows, glazed components and those that transfer heat to the ground, as well as components, through which air supply is expected. Heat transfer coefficient is an important parameter that allows for determining the thermal properties of a partition. It is defined for homogeneous-layer building partitions, building partitions with at least one composite layer and for components with layers of varying thickness.

The heat transfer coefficient is expressed by the equation:

$$
U=\frac{1}{R_{T}},\left[\frac{W}{m^{2} \cdot K}\right]
$$

Where:

$\mathrm{R}_{\mathrm{T}}$ - total thermal resistance of a building partition

Total thermal resistance $\mathrm{R}_{\mathrm{T}}$ for homogeneous partitions is described by the formula:

$$
\mathrm{R}_{\mathrm{T}}=\mathrm{R}_{\mathrm{si}}+\mathrm{R}_{1}+\mathrm{R}_{2}+\ldots+\mathrm{R}_{\mathrm{n}}+\mathrm{R}_{\mathrm{se}},\left[\frac{m^{2} \cdot K}{W}\right]
$$

Where:

$\mathrm{R}_{\mathrm{si}}$ - heat transfer resistance on the inner surface

$\mathrm{R}_{1}+\mathrm{R}_{2}+\ldots+\mathrm{R}_{\mathrm{n}}$ - design thermal resistance of each layer $\mathrm{R}_{\mathrm{se}}$ - heat transfer resistance on the outer surface

Thermal resistance of a homogeneous layer with thickness $d$ is obtained from the equation:

$$
R=\frac{d}{\lambda},\left[\frac{m^{2} \cdot K}{W}\right]
$$

Where:

$\mathrm{d}$ - thickness of the material

$\lambda$ - design thermal conductivity of the material

The PN-EN ISO 13788 [5] standard presents a simplified method of calculating the temperature of the inner surface of the building component, under which, at a known temperature and humidity of indoor air, mould or condensation on surfaces can develop. It also provides methods for assessing the risk of indoor condensation due to water vapour diffusion. The risk of mould growth occurs at relative humidity above $80 \%$ for several days. To prevent the formation of mould, it is important to fulfil the condition:

$\mathrm{f}_{\mathrm{Rsi}}>\mathrm{f}_{\mathrm{Rsi} \text { min }}$

where:

$\mathrm{f}_{\mathrm{Rsi}}$ - temperature on the inner surface,

$\mathrm{f}_{\mathrm{Rsi}, \mathrm{min}}$ - minimum permissible temperature on the inner surface, determined on the basis of the internal and external climate.
The calculation is carried out for each month of the year [6]. The internal humidity and acceptable volumetric moisture at saturation are determined. It is also possible to calculate the partial pressure of saturated steam at the surface and assume a critical relative humidity at the surface. Then, the minimum temperature of the analysed area is determined.

To calculate the temperature and humidity parameters, a partition composed of homogeneous layers without a layer of air is used. In order to simplify the calculations it was assumed that the supporting structure made of the timber, if it is constructed on the entire thickness of the wall as a continuous structure, has no substantial effect on the conduction of heat through the wall. This is associated with a large wall insulation thickness in relation to the cross-section of the superstructure columns. Flow of heat takes place in the horizontal direction, which is defined by $\mathrm{R}_{\mathrm{si}}=0.13$ and $\mathrm{R}_{\mathrm{se}}=0.04$. Internal moisture conditions are adopted for constant internal temperature of $20^{\circ} \mathrm{C}$ and a constant relative humidity of $50 \%$. When checking the criterion for preventing surface condensation of partitions, regardless of the type of partition, the heat transfer resistance value on the inner surface of the partition of R$\mathrm{si}=0.25\left[\frac{\mathrm{m}^{2} \cdot \mathrm{K}}{\mathrm{W}}\right]$ is adopted.

The first step compares the heat transfer coefficients for different wall thickness, made in straw-bale and light clay technology (Figure 1.). The analysis was performed for the same wall thicknesses, calculated together with the clay plaster. In the case of light clay, double-sided plaster with a thickness of $3 \mathrm{~cm}$ on each side was used. For straw bales, $7 \mathrm{~cm}$ of external plaster and $4 \mathrm{~cm}$ of internal plaster was assumed.

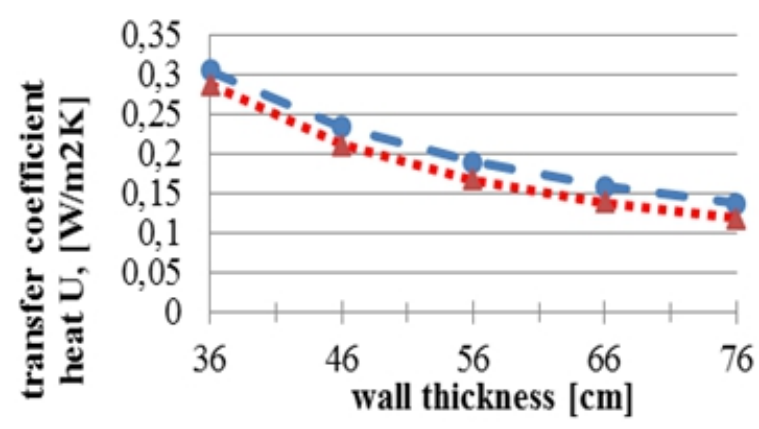

Figure 1. Comparison of the heat transfer coefficients for different thicknesses of walls made of light clay $\bullet$ or pressed straw $\bullet$ (Source: own work)

"Regulation on technical conditions to be met by buildings and their location" gives the limit value of heat transfer coefficient $U=0.25\left[\mathrm{~W} / \mathrm{m}^{2} \mathrm{~K}\right]$ for the outer wall. In addition to meeting the requirements of heat transfer, it is worth considering the optimal thickness of the walls. Due to the low cost of insulating the walls, it is best to choose the thickness of about $50 \mathrm{~cm}$. This will create a well-insulated partition, satisfying, e.g. in the case of straw bales, almost twice the thermal requirements. It will also have an appropriate heat storage mass and greater rigidity. At the same time, the wall thickness of about $50 \mathrm{~cm}$ will provide the required sound insulation. The use of thicker insulating material is 
associated with a greater reduction in living space and possible higher costs of the wooden frame. The following section presents a thermal and moisture analysis of a building with wall thickness of $56 \mathrm{~cm}$ (Table 1, Table 2.).

Construction of a partition:

Table 1. Properties of the light clay wall materials used.

\begin{tabular}{|l|l|c|c|c|c|c|}
\hline \multirow{2}{*}{ No } & \multirow{2}{*}{ The layer } & $\mathrm{d}$ & $\lambda$ & \multirow{5}{*}{$\mu$} & $\mathrm{R}$ & $\mathrm{S}$ \\
\cline { 3 - 4 } & {$[\mathrm{m}]$} & {$[\mathrm{W} / \mathrm{mK}]$} & & {$\left[\mathrm{m}^{2} \mathrm{~K} / \mathrm{W}\right]$} & {$[\mathrm{m}]$} \\
\hline Outside & & 0,03 & 0,58 & 10 & 0,052 & 0,3 \\
\hline 1 & clay plaster & 0,5 & 0,1 & 10 & 5 & 5 \\
\hline 2 & light clay & 0,03 & 0,58 & 10 & 0,052 & 0,3 \\
\hline 3 & clay plaster & \\
\hline
\end{tabular}

Table 2. Properties of the straw bale wall materials used.

\begin{tabular}{|c|l|c|c|c|c|c|}
\hline \multirow{2}{*}{ No } & \multirow{2}{*}{ The layer } & $\mathrm{d}$ & $\lambda$ & \multirow{5}{*}{$\mu$} & $\mathrm{R}$ & $\mathrm{S}$ \\
\cline { 3 - 4 } \cline { 7 - 8 } & {$[\mathrm{m}]$} & {$[\mathrm{W} / \mathrm{mK}]$} & & {$\left[\mathrm{m}^{2} \mathrm{~K} / \mathrm{W}\right]$} & {$[\mathrm{m}]$} \\
\hline Outside & \\
\hline 1 & clay plaster & 0,07 & 0,58 & 10 & 0,121 & 0,7 \\
\hline 2 & straw bale & 0,45 & 0,08 & 1,3 & 5,625 & 0,585 \\
\hline 3 & clay plaster & 0,04 & 0,58 & 10 & 0,069 & 0,4 \\
\hline Inside &
\end{tabular}

The effective value of the temperature coefficient on the inner surface of the barrier is determined by the value of heat transfer coefficient U element and the heat transfer resistance at the inner surface $\mathrm{R}_{\mathrm{si}}$.

For light clay:

Total thermal resistance of a partition: $R_{t}=5.273\left[\mathrm{~m}^{2} \mathrm{~K} / \mathrm{W}\right]$ The heat transfer coefficient of the building partition (without taking into account corrections for leakage and connectors $\Delta \mathrm{U}$ and allowance for linear bridges $\Delta \mathrm{Uk}$ ): $\mathrm{U}=0.19\left[\mathrm{~W} / \mathrm{m}^{2} \mathrm{~K}\right]$

The value of temperature coefficient for the partition: $\mathrm{f}_{\mathrm{Rsi}}=0.968$

For straw bale:

Total thermal resistance of a partition: $\mathrm{R}_{\mathrm{t}}=5.985\left[\mathrm{~m}^{2} \mathrm{~K} / \mathrm{W}\right]$ The heat transfer coefficient of the building partition (without taking into account corrections for leakage and connectors $\Delta U$ and allowance for linear bridges $\Delta U \mathrm{Uk}$ ): $\mathrm{U}=0.167\left[\mathrm{~W} / \mathrm{m}^{2} \mathrm{~K}\right]$

The value of temperature coefficient for the partition: $\mathrm{f}_{\mathrm{Rsi}}=0.972$

Due to the same value for the temperature coefficient of the two partitions, a minimum value of the $f_{R s i}$ coefficient in individual months is as follows (Table 3.):
Table 3. Value of the minimum $f_{\text {Rsi }}$ coefficient.

\begin{tabular}{|c|c|c|}
\hline & Months & fRsi, min \\
\hline 1 & January & 0,679 \\
\hline 2 & February & 0,659 \\
\hline 3 & March & 0,583 \\
\hline 4 & April & 0,385 \\
\hline 5 & May & $-0,054$ \\
\hline 6 & June & $-1,235$ \\
\hline 7 & July & $-2,688$ \\
\hline 8 & August & $-1,837$ \\
\hline 9 & September & $-0,117$ \\
\hline 10 & October & 0,359 \\
\hline 11 & November & 0,548 \\
\hline 12 & December & 0,64 \\
\hline
\end{tabular}

The highest value $f_{\text {Rsi,min }}=0.679$ was obtained for the critical month of January. the condition that $\mathrm{f}_{\mathrm{Rsi}}=0.968>\mathrm{f}_{\mathrm{Rsi}, \mathrm{min}}=0.679$ is met. Therefore, the analysed building partitions are designed properly in terms of avoiding mould growth.

The calculated value of the dew point temperature is $\mathrm{T}_{\mathrm{s}}=9.23^{\circ} \mathrm{C}$ for all months of the year. This indicates that the temperature on the inner surface of the building partition, which fluctuates around $19.5^{\circ} \mathrm{C}$, is higher than the dew point temperature plus $1^{\circ} \mathrm{C}$. Partitions were therefore designed in accordance with the technical requirements (Regulation of the Minister of Infrastructure of 12 April 2002) on the dew point.

\section{Conclusion}

Construction using light clay and straw is still not very common. Lack of standardisation of straw as a building material, as well as the old standards for building using clay are a major barrier against the rapid development of this type of natural building in Poland $[7,8,9]$. There is a lack of promotion, modern scientific and research base that could afford to put these materials on the construction market on an industrial scale. On the other hand, rapidly vanishing natural resources, rising energy costs and tightening thermal standards of the European Union may soon help change the attitude of the state and the people to natural building methods. These technologies are needed as they make it possible to reduce $\mathrm{CO}_{2}$ emissions and reduce environmental pollution $[10,11,12]$.

The thermal analysis showed a very good performance for both walls made of straw bale and of light clay.

All these positive aspects, as well as good thermal calculation results allow treating straw and light clay with full responsibility as a viable alternative to the commonly used technologies for erecting buildings.

\section{References}

1. Law on construction products of 16 April 2004

2. PN-EN ISO 6946:2008 Building components and building elements

3. $\mathrm{BN}-62 / 6738-01$, Masses of cement - clay fillers

4. $\mathrm{BN}-62 / 6738-02$, Construction of clay. The masses of clay 
5. $\mathrm{BN}-62 / 8841-04$, Construction of clay. The walls of rammed clay. Technical conditions for execution and acceptance

6. PN-EN ISO 13788:2003 Thermal and moisture properties of building components and building elements

7. M. Hyła, D. Kupiec-Hyła, Houses of light clay Guide, Published by: Grupa Cohabitat on Feb 20, 2011

8. M. Zatylny, Formal and legal conditions for natural building in Europe and Poland with particular emphasis on the application of straw bale, United Nations Development Programme, Warszawa 2011

9. M. Jagielak, Building with straw bale in Poland against the general characteristics of this technology, United Nations Development Programme, Warszawa 2011

10. A. Lecyk, Architecture inherently -low-tech, Intelligent Building No. 5/2012

11. B. Backiel - Brzozowska, Construction of clay and straw - Preliminary assessment of selected aspects of sustainability, Environmental Engineering, 40/2014

12. M. Spisakova, D. Maćkova, The Use Potential of Traditional Building Materials for the Realization of Structures by Modern Methods of Construction, Journal of Civil Engineering, December 2015 